\title{
Trends in Health Behavior and Weight Outcomes Following Enhanced Afterschool Programming Participation: A Pragmatic Quasi-experimental Study
}

\author{
Jessica Rieder ( $\nabla$ jrieder@montefiore.org ) \\ Jee-Young Moon \\ Albert Einstein College of Medicine \\ Joanna Joels \\ Children's Hospital at Montefiore \\ Viswanathan Shankar \\ Albert Einstein College of Medicine \\ Paul Meissner \\ Montefiore Medical Center \\ Elicia Johnson-Knox \\ Children's Hospital at Montefiore \\ Bailey Frohlich \\ Children's Hospital at Montefiore \\ Shelby Davies \\ Children's Hospital of Philadelphia \\ Judy Wylie-Rosett \\ Albert Einstein College of Medicine
}

Associate Professor of Pediatrics Children's Hospital at Montefiore 3415 Bainbridge Avenue Bronx, NY https://orcid.org/0000-0002-7280-1013

\section{Research article}

Keywords: Health behaviors, school health, physical activity, afterschool programming, target behaviors, sleep, healthy eating, breakfast, lunch, adolescent obesity, Wellness Cascade, Adolescents, Obesity, Weight Management, Community Intervention, Wellness

Posted Date: September 10th, 2020

DOI: https://doi.org/10.21203/rs.3.rs-68810/v1

License: (c) (1) This work is licensed under a Creative Commons Attribution 4.0 International License. Read Full License

Version of Record: A version of this preprint was published at BMC Public Health on April 7th, 2021. See the published version at https://doi.org/10.1186/s12889-021-10700-4. 


\section{Abstract}

Background: The United States needs to increase access to effective obesity prevention and treatment programming for impoverished youth at risk for health disparities. Although interventions targeting schools are recommended, schools rarely implement evidence-based obesity programing.

Methods: Using a pragmatic quasi-experimental design, we report on the effectiveness of adding structured nutrition education and minimum physical activity (PA) requirements to standard middle school onsite afterschool programming. Programming was evaluated over three school years (2016-2018) to determine: 1) impact on healthy weight and target healthy behavior attainment; and 2) whether target behavior improvement was associated with afterschool program attendance and weight change.

Results: In response to 601 recruitment letters $13 \%$ (76 students) enrolled (62\% Hispanic, $46 \%$ girls, $72 \%$ with BMI $\geq 85$ th $\%$ ile, $49 \%$ with $\mathrm{BMI} \geq 95$ th $\%$ ile). With low baseline attainment of 7 target behaviors including:1) daily breakfast and lunch (32\%); 2) 2-3 servings fruit/day (53\%); 3) $\geq 3$ servings vegetables/day (29\%); 4) 8 cups sugar-free beverages (SFB)/day and $<1$ cup sugary beverage/day (9\%); 5 ) $\geq 8$ hours sleep/night (75\%); 6$) \geq 7$ hours PA/week (21\%); and 7$) \leq 1$ unhealthy snack (US) and $<1$ fast food meal/week (25\%), the calculated composite score was 2.5 out of 7 . Of students with $\mathrm{BMI} \geq 85$ th $\%$ ile, $44 \%$ maintained or decreased BMI Z-score. There were non-significant trends in improvements in BMI Z-score and target consumption of: fruit, vegetables, SFB, and US food. Students with higher afterschool attendance $(\geq 75 \%)$ had greater non-significant improvements in composite score, BMI Z-score, and in most target behaviors $(5 / 7)$ compared to students with lower afterschool attendance ( $<75 \%)$. Although not significant, improvements in composite score attainment and most target behaviors (5/7) were associated with decreases in BMI Z-score. Sleep improvements were significantly associated with BMI Z-score decrease (Beta=-0.05, 95\% $\mathrm{Cl}(-0.1,-0.003), \mathrm{p}=0.038$.)

Conclusions : Enhancement of existing afterschool programming with health oriented elements and minimum physical activity requirements demonstrates trends toward improvement in several health behaviors and weight outcomes. Addition of enhanced programming increases access to health activities and may bring us closer to solving issue of obesity in at-risk youth in impoverished communities.

Trial registration: ClinicalTrials.gov identifier (NCT number): NCT03565744. Registered 21 June 2018 - Retrospectively registerd, https://register.clinicaltrials.gov/prs/app/action/LoginUser?ts=1\&cx=-jg9qo4.

\section{Introduction}

The prevalence of obesity in the United States is $\sim 1$ in 5 in 2-19 year-old children and adolescents,[1,2] and the most severe forms of obesity are increasing, particularly among adolescents and non-Hispanic blacks.[3] Low socioeconomic (SES) children are 1.4 times more likely to be obese, and low SES ethnic minority adolescents are less likely to live in neighborhoods supportive of physical activity than higher SES Caucasian youth.[4,5] The low SES of teens living in low-income urban environments limits their exposure to opportunities that can make a difference in their lives and reduce health disparities compared with other teens.[6] Simulation models indicate that childhood overweight and obesity will continue to be a significant health problem in the United States and that obesity in adolescence increases the risk for many chronic conditions.[7] Effective preventive and treatment interventions are lacking, especially for minority youth at risk for health disparities and the most severe forms of obesity.[8-10]

The U.S. Preventive Services Task Force (USPSTF) recommendations to promote improvements in weight status and cardiovascular and metabolic risk factors include referral of children and adolescents with obesity to comprehensive, intensive behavioral interventions that are moderate to high intensity ( $>26$ contact hours over 2-12 months).[8] Depending on the degree of overweight or obesity, staged interventions with increasing intensity of care provided by a multidisciplinary health care team of medical providers, nutritionists, mental health providers, exercise specialists and health coaches featuring physical activity, nutrition, and sedentary behavior reduction counseling, parental involvement, and cultural tailoring are recommended.[9,11,12] While such intensive weight management programs can decrease weight and risk for developing type 2 diabetes mellitus (DM),[9,12-14] they tend to be offered in highly specialized treatment centers, are demanding of patients, and require highly trained staff.[15] Effective andless intensive, large-scale public health efforts that target youth in schools or communities tend to focus on the prevention of obesity, rather than addressing the needs of youth with pre-existing obesity and severe obesity. While they engage and promote healthy lifestyle behaviors for large numbers of youth, often they lack comprehensive services, and many have not demonstrated favorable effects on BMI.[9,16-18] Further, the Community Preventive Services Task Force (CPSTF) has found insufficient evidence to recommend school-based obesity programs to prevent or reduce overweight and obesity among children and adolescents.[19] In a cross-sectional survey of schools conducted in 2016 , Kenney et al. found that slightly less than half ( $n=117,47.4 \%$ ) of schools surveyed offered any obesity prevention program; only $17(6.9 \%)$ reported using a predeveloped program, and 7 (2.8\%) reported using a program with evidence for effectiveness.[20]

The increased costs of interventions and health care in resource-limited environments have fueled the demand for applicable evidence for effective weight management programs that can be integrated into existing school programming environments. The programs that decrease the trajectory of weight gain also address the needs of high-risk youth with obesity and severe obesity. We piloted the B'N Fit POWER initiative, a middle school-based comprehensive wellness program, and partnered with a school and its onsite stakeholders. The initiative integrates weight management programming into existing onsite afterschool programming and school-based health center clinical services.[21] Our initial implementation strategies are reported elsewhere.[22] This paper reports on the effectiveness of adding structured nutrition education and a minimum requirement for physical activity to standard middle school-based afterschool programming.

\section{Methods}

We used a pragmatic quasi-experimental study to evaluate the effectiveness of the $B$ 'N Fit POWER initiative on weight reduction and target behavioral attainment in real-life conditions and to maximize its generalizability. The data was collected using a repeated cross-sectional design over three school years 
2016 -2018. The primary aim is to evaluate if 1) enhanced afterschool programming effectively improves healthy weight and target healthy behavior attainment, and 2) program component completion rates were associated with improvements in BMI-Z-scores, and target outcome behaviors. The Montefiore -Einstein Institutional Review Board approved the study. Parents provided verbal consent and HIPAA authorization, and students provided assent at their initial School-BasedHealth Center (SBHC) visit.

\section{Setting/Partner Stakeholders}

The study is set in the Bronx, NY, which is the nation's poorest urban county, consistently New York State's least healthy county, and with a predominantly minority community (56\% Hispanic, 44\% African-American).[23] The Bronx has the highest proportion of children living below poverty in the United States and $21 \%$ of children below age 6 in deep poverty.[24] School absenteeism is high, school completion rates are low (71\%), unemployment is high ( $25 \%$ ), residents have low access to recreation and facilities (3.25 facilities per 100,000 residents), and 77\% of Bronx residents are likely to be living a geographic area designated as a "Health Professional Shortage area," which likely contributes to low health care access and more health issues.[25-27] At a prevalence rate of $22.3 \%$, rates of obesity among over 240,0000 school-age children in the Bronx are higher than other boroughs in NYC and also higher than the national estimates.(23,28-30).

In the winter before each of 2016-17, 2017-18, and 2018-19 school years, the MMCC afterschool program director sent an opt-out letter home to the parents of all $5^{\text {th }}$-8th grade PS/MS-95 students registered in the MMCC afterschool program (identified via the NYC Department of Youth and Community Development (DYCD) registration database). Parents were informed to contact the MMCC program director if they did not want their child to participate in a health assessment, which included height and weight measurement and BMI determination. A total of 601 letters were sent home via backpack, letters were not required to be returned, and no parents declined participation. At the start of the school year, following health screening, parents were invited to enroll their children in $B^{\prime} N$ Fit POWER (Enhanced program) middle school-based afterschool programming. Inclusion criteria for a $B^{\prime} N$ Fit POWER invitation were that the student had to be 11 to 14 years, going to be in the $6^{\text {th }}-8^{\text {th }}$ grade in the fall of the upcoming school year, and interested in registering in both the MMCC afterschool program and the MSHP SBHC. Students were excluded if they had a mental illness rendering them incapable of providing assent for research or complying with the afterschool program protocol or had medical problems that made it unsafe for them to participate in the program. Enrollment was capped at 40 students for the first two years and 20 students for the third year based on staff and resource availability and programming capacity. The target enrollment initially was to recruit at least $85 \%$ of program students with a BMI $\geq 85^{\text {th }}$ percentile. Enrollment in the second year dropped related to the stigma surrounding participating in a program for overweight youth. Thus, the recruitment objective was dropped for the third year. (See Figure1).

Weekly B'N Fit POWER program requirements included: 1) three 45-minute (total 2.25 hours) $B^{\prime} N$ Fit POWER leadership sessions, and 2) at least 5 hours of physical activity program. The leadership sessions included the $B^{\prime} N$ Fit POWER leadership curriculum, cooking class, and core physical activity education. Consistent with the American Academy of Pediatrics Expert Committee, Physical Activity Guidelines for Americans 2nd Edition NHLBI sleep recommendations, and USDA MyPlate guidelines,[11,33-35] B'N Fit POWER leadership curriculum taught concepts supporting the attainment of "ideal" or recommended 7 Target Behaviors: 1) eat breakfast and lunch daily; 2 ) eat 2-3 servings of fruits/day; 3 ) eat $\geq 3$ servings vegetables/day; 4 ) drink 8 cups of water and limit sugary beverages to $\leq 1 /$ day; 5) sleep at least 8 hours/night; 6 ) get $\geq 1$ hour of physical activity/day; and 7) eat unhealthy snack foods and fast foods no more than weekly. The five hours of physical activity consisted of the 45-minutes core physical activity education leadership session plus an additional 4.25 hours during the non-leadership "Physical Activity" program. Since we were not able to distinguish which of the 2.25 hours of leadership each week consisted of the physical activity instruction, the target goal for physical activity hours per week was adjusted to 4.25 hours minimum. With 36 weeks of programming a year, each student was scheduled to have 81 hours a year of leadership (with 75\% expected attendance at 60.75 hours) and 153 hours of physical activity (with $75 \%$ expected attendance at 114.75 hours.) Students enrolled in the enhanced $B^{\prime} N$ Fit POWER program all received comprehensive medical assessments at the MSHP SBHC as well as core MMCC afterschool program services, which included three 45-minute leadership, literacy, and Science, Technology, Engineering and Mathematics (STEM) session requirements.

\section{$\underline{\text { Outcome Metrics }}$}

The process (implementation) evaluation metrics of this study measuring the proportion of students attaining the Wellness Cascade milestone steps, including assessment, enrollment, engagement, and completion of comprehensive wellness programming, are presented elsewhere.[22]

Outcome metrics were determined with stakeholder input considering relevant measures commonly obtained and utilized by the partners with the potential to ascertain data that would be accurate, credible, and reproducible measures of progress. Primary outcomes included: 1) Height and weight collected up to four times a year either by SBHC nursing staff during routine clinical assessments or by the school's Physical Education staff as part of the annual Fitnessgram ${ }^{\circledR}$ assessments. BMI's derived were categorized into four groups a) normal if BMI $\geq 5^{\text {th }}$ and $<85^{\text {th }} \%$ ile; b) overweight if $B M l s ~ \geq 85^{\text {th }}$ and $<95^{\text {th }} \%$ ile; $c$ ) obese if BMls $\geq 95^{\text {th }}$ and $<99^{\text {th }} \%$ ile; and d) severely obese if BMls $\geq 99^{\text {th }} \%$ ile.[36] 2)Target behavior attainment was assessed up to four times a year using a 14-item survey either by SBHC clinical staff during routine clinical assessments or by MMCC afterschool staff as part of afterschool health screening done annually. [21] Clinic data was obtained from the Epic EHR database, and attendance at afterschool sessions was monitored using the MMCC afterschool NYC DYCD database.

Statistical Methods:

\section{Results}

Wellness Cascade Milestone Steps: 
Following the wellness cascade approach, we tracked progress and outcomes of all available students ( program effectiveness) as well subset of students with a $\mathrm{BMI} \geq 85^{\text {th }} \%$ ile (cascade effectiveness). We approached 601 students who were registered and eligible for screening at the MMCC afterschool program between 2016 to 2018. Of the students, 403 had demographic data and were assessed ( $n=198$ were absent on health screening days). Three hundred and twenty-four had screening BMI data over the three school years, and of those, 180 had a BMI>85th\%ile (56\% of those with BMI screening data) (Step 1 - see Figure 1). A total of 79 students assented and enrolled ( 56 with BMl>85th\%ile) (Step 2) in B'N Fit POWER by registering in both SBHC and MMCC. A total of 76 students attended at least one clinic and one afterschool session and thus engaged (55 with BMl>85th\%ile) (Step 3) in the B'N Fit POWER program. A total of 65 students participated at all three clinic visits and completed the program ( 48 had BMl $\geq 85^{\text {th }} \%$ ile) (Step 4). Finally, 24 students (21 with BMI>85th\%ile) demonstrated either maintenance or an improvement in BMI z-score (Step 5).

\section{Baseline Student Characteristics}

Table 1 summarizes the demographic and baseline anthropometric information of the $B^{\prime} N$ Fit POWER students that were engaged in three academic years $(\mathrm{N}=76)$. Students were predominantly Hispanic/Latino (62\%), and $46 \%$ of students were girls. A majority ( $80 \%)$ were overweight or obese, and over half $(53.6 \%)$ were obese or severely obese. At baseline, average BMI Z-score was 1.4 (0.8). Overall, there was low attainment of target behaviors at baseline, with $32 \%$ of students eating breakfast and lunch daily, $53 \%$ eating $2-3$ servings of fruit daily and $29 \%$ eat $3-6$ servings of vegetables daily, $29 \%$ drinking 8 cups of sugar-free beverages daily, $75 \%$ sleeping at least 8 hours a night, $21 \%$ participating in at least 7 hours of physical activity weekly, $25 \%$ eating no more than one unhealthy snack or fast food meal weekly. The overall target behavior composite score was $2.5(\mathrm{SD}=1.1)$. Comparison of baseline target behaviors by grade, demonstrates that while not significant due to limited sample size, there was a trend of a $5 \%-10 \%$ decline in target attainment of lunch consumption, sugarfree beverage consumption, sugary beverage consumption, unhealthy snack food consumption and fast food consumption from age 11 to 13 years.

\section{$\underline{T a b l e ~} 1$}

\section{B'N Fit POWER 2016-2018 Baseline Student Characteristics}




\begin{tabular}{|c|c|c|}
\hline & $\begin{array}{l}B^{\prime} N \text { Fit POWER } \\
\text { All Students } \\
(\mathrm{N}=76)\end{array}$ & $\begin{array}{l}B^{\prime} N \text { Fit Power } \\
\text { Cascade Target students }\left(\geq 85^{\text {th }} \% \text { ile }\right) \\
(\mathrm{N}=55)\end{array}$ \\
\hline \multicolumn{3}{|l|}{ Demographics } \\
\hline 2016 & 35 & 30 \\
\hline 2017 & 27 & 17 \\
\hline 2018 & 14 & 8 \\
\hline Age, yrs (SD) & $12.4(1.0)$ & $12.5(1.1)$ \\
\hline Sex, Female, \% & $35(46.1)$ & $25(45.5)$ \\
\hline \multicolumn{3}{|l|}{ Ethnicity } \\
\hline Black (Non-Hispanic) & $19(25)$ & $14(25)$ \\
\hline Hispanic/Latino & $47(61.8)$ & $32(58)$ \\
\hline White (Non-Hispanic) & $3(3.9)$ & $3(5)$ \\
\hline \multicolumn{3}{|l|}{ Anthropometrics: $\bar{x} \pm S D$} \\
\hline $\mathrm{BMI}, \mathrm{kg} / \mathrm{m} 2$ & $24.7(3.8)$ & $26.2(2.3)$ \\
\hline BMI percentile, \% & $86.7(20.1)$ & $95.1(3.6)$ \\
\hline BMI Z-score & $1.4(0.8)$ & $1.7(0.3)$ \\
\hline \multicolumn{3}{|l|}{ Obesity category } \\
\hline BMI (5- 84.9\%ile) Healthy weight & $14(20.3)$ & $0(0)$ \\
\hline BMI (85-94.9\%ile) Overweight & $18(26.1)$ & $18(32.7)$ \\
\hline BMI (95-98.9\%ile) Obesity & $33(47.8)$ & $33(60)$ \\
\hline BMI (>99\%ile) Severe obesity & $4(5.8)$ & $4(7.3)$ \\
\hline \multicolumn{3}{|l|}{ Baseline Attainment of Target behaviors (\%) } \\
\hline Breakfast daily & $34(45.3)$ & $25(46.3)$ \\
\hline Lunch daily & $43(57.3)$ & $29(53.7)$ \\
\hline Breakfast and Lunch daily & $24(32)$ & $17(31.5)$ \\
\hline Fruit (2-3 servings/day) & $40(53.3)$ & $29(53.7)$ \\
\hline Vegetable ( 3-6 servings/day) & $22(29.3)$ & $16(29.6)$ \\
\hline Sugarfree Beverages ( 8 cups a day) & $21(28.8)$ & $15(28.8)$ \\
\hline Sugary Beverages ( $\leq 1$ cup a day) & $20(26.7)$ & $15(27.8)$ \\
\hline Sugarfree and Sugary Beverages ( 8 cups $\& \leq 1$ cup a day) & $7(9.3)$ & $5(9.3)$ \\
\hline Sleep ( at least 8 hours a night) & $56(74.7)$ & $41(75.9)$ \\
\hline Physical activity ( $\geq 1$ hour of physical activity/day) & $16(21.3)$ & $12(22.2)$ \\
\hline Unhealthy snacks ( no more than weekly) & $20(27)$ & $16(29.6)$ \\
\hline Fast foods ( no more than weekly) & $53(70.7)$ & $37(68.5)$ \\
\hline Unhealthy snack and fast foods (no more than weekly) & $19(25.3)$ & $15(27.8)$ \\
\hline Composite score (SD), range: 0-7 & $2.5(1.1)$ & $2.5(1.1)$ \\
\hline
\end{tabular}

\section{Afterschool Program and Clinic Attendance}

The overall afterschool leadership and physical activity attendance following one academic year was $63.7( \pm 23.6)$ hours and $67.9( \pm 39.3)$ hours, respectively. That is, the students participated less than expected -1.8 hours per week in leadership ( $80 \%$ of expected 2.25 hours) and 1.9 hours per week in physical activity (45\% of expected 4.25 hours). Participation at the clinic visits was high, with $85.5 \%(65 / 76)$ attending all three visits. Yet, participation in all three clinic visits and at least $75 \%$ attendance at leadership and physical activity was low at $15.8 \%(12 / 76)$. 
Comparing baseline and $4^{\text {th }}$ visit, students engaged in the $B^{\prime} N$ Fit POWER program showed negligible change in BMI Z-score of 0.02 (SE=0.03, $p=0.29$ ). Multiple imputation (MI) showed a similar result of -0.04 (SE=0.15). Similarly, we did not observe any significant change in composite score over time (mean change $=0, \mathrm{SE}=0.21, p=0.96$ ) (Figure 2). The BMI Z-score change in the cascade target students was 0.01 (SE: $0.04, p=0.49$ ), while not statistically significant, the change in composite score was -0.22 (SE: $0.24, p=0.47$ ) suggesting a potential narrowing of uptake of expected negative behaviors.

Assessment of changes in each individual target behavior showed progress in some target behaviors (Figure 3): fruit and vegetable consumption, combined increased consumption of sugar-free beverages with decreased sugary beverages, and improved unhealthy snack food consumption following participation in the program. Students, however, lacked progress in breakfast, lunch $(p=0.05)$, fast food, sugary beverage consumption, and target sleep hours. Similarly, multiple imputation result suggested a marginally significant increase in vegetable consumption $(p=0.07)$, a decrease in breakfast consumption ( $p=0.09)$ and increase in eating fast food $(p=0.05)$. Individual behavioral changes in the cascade target students suggested a similar positive progress in percentages as in the total program students. (Supplementary Figure 1)

As target behaviors were measured four times over the academic year, we assessed the trajectory in behavior changes using the repeated measures with similar results. A non statistically significant trend in composite score over time showed that students demonstrated progress in vegetable and fruit consumption, sugar free and sugary beverage consumption, physical activity, and unhealthy snack consumption. (Supplementary Table 1). Multiple imputation results showed similar magnitudes in the forementionned target behaviors except for the composite score, fruit consumption, and physical activity.

When examining how target behavior trajectory change over time differed with afterschool attendance, though not statistically significant, assuming the baseline risks are the same between groups, students with $\geq 75 \%$ afterschool attendance at leadership (which included nutrition education and cooking classes) and physical activity had higher tendency for target behavior improvement, including a 3.6 fold increase in fruit consumption and a 4.2 fold increase in drinking less surgary beverages, compared to students with lower afterschool attendance (<75\%) (Table 2). Mulitple imputation result showed similar results. The cascade target students who had higher after school attendance showed progress in BMI Z-score, fruit (OR: 5.93, 95\%Cl: 0.85, 41.46) and vegetable (OR: $1.62,95 \% \mathrm{Cl}: 0.11,23.02)$ consumption. They also showed improved progress in physical activity and eating less unhealthy snacks target behavior attainment. ( Supplemental Table 2)

\section{$\underline{\text { Table } 2}$}

Target behavior change for Low ( $\leq 75 \%)$ and High ( $>75 \%)$ Afterschool Attendance* 


\begin{tabular}{|c|c|c|c|c|c|c|}
\hline & \multicolumn{6}{|c|}{ Afterschool Attendance } \\
\hline & \multicolumn{3}{|l|}{ Low } & \multicolumn{3}{|l|}{ High } \\
\hline & \multicolumn{3}{|c|}{$N=56(78 \%)$} & \multicolumn{3}{|c|}{$N=16(22 \%)$} \\
\hline & \multirow{2}{*}{\multicolumn{3}{|c|}{$\begin{array}{l}\text { Mean attendance } \\
\text { (3.1 hrs/week) }\end{array}$}} & \multirow{2}{*}{\multicolumn{3}{|c|}{$\begin{array}{l}\text { Mean attendance } \\
\text { (5.7 hrs/week) }\end{array}$}} \\
\hline & & & & & & \\
\hline Outcome & $\beta$ & $95 \% \mathrm{Cl}$ & P-value & $\beta$ & $95 \% \mathrm{Cl}$ & P-value \\
\hline Composite Score* & 0.07 & $(-0.37-0.51)$ & 0.745 & 0.16 & $(-0.65-0.97)$ & 0.700 \\
\hline BMI Z-score & 0.00 & $(-0.05-0.06)$ & 0.923 & 0.02 & $(-0.08-0.12)$ & 0.632 \\
\hline Behavior & OR & $95 \% \mathrm{Cl}$ & P-value & OR & $95 \% \mathrm{Cl}$ & P-value \\
\hline Breakfast & 0.80 & $(0.23-2.77)$ & 0.728 & 0.96 & $(0.12-7.69)$ & 0.969 \\
\hline Lunch & 0.37 & $(0.11-1.24)$ & 0.108 & 0.00 & $(0-0.1)$ & 0.001 \\
\hline Breakfast \& Lunch & 0.88 & $(0.26-2.9)$ & 0.828 & 0.30 & $(0.03-3.48)$ & 0.334 \\
\hline Fruit & 0.98 & $(0.42-2.28)$ & 0.965 & 3.55 & $(0.65-19.29)$ & 0.143 \\
\hline Vegetable & 2.07 & $(0.67-6.37)$ & 0.204 & 2.22 & $(0.24-20.79)$ & 0.484 \\
\hline Sugar Free Beverage & 1.09 & $(0.35-3.32)$ & 0.886 & 0.90 & $(0.12-6.73)$ & 0.922 \\
\hline Sugary Beverage & 0.63 & $(0.2-1.91)$ & 0.411 & 2.64 & $(0.31-22.59)$ & 0.376 \\
\hline Sugar-Free and Sugary Beverage & 1.13 & $(0.25-5.09)$ & 0.877 & 1.83 & $(0.12-28.91)$ & 0.669 \\
\hline Sleep & 0.83 & $(0.25-2.75)$ & 0.762 & 0.24 & $(0.03-1.92)$ & 0.179 \\
\hline Physical activity & 1.09 & $(0.28-4.22)$ & 0.905 & 1.59 & $(0.15-16.35)$ & 0.698 \\
\hline Unhealthy snacks & 1.25 & $(0.46-3.4)$ & 0.660 & 1.55 & $(0.21-11.6)$ & 0.668 \\
\hline Fast Food & 0.55 & $(0.19-1.58)$ & 0.268 & 0.38 & $(0.07-2.19)$ & 0.281 \\
\hline Unhealthy Snack and Fast Food & 0.77 & $(0.27-2.18)$ & 0.627 & 0.82 & $(0.07-9.33)$ & 0.870 \\
\hline
\end{tabular}

*- 4 students were missing afterschool attendance data

\section{$\underline{\text { Associations Between Target Behavior Change and BMI Z-score }}$}

Although not significant, improvements in individual target behaviors and composite score showed progress in BMI Z-score reduction. This was seen especially in those students who had accomplished the target sleep hours with a statistically significant decrease in BMI Z-score $(\beta=-0.05,95 \% \mathrm{Cl}-0.1-$ $-0.003, p=0.038$ ) (Table 3). Cascade target students showed similar trends as whole program participants especially with respect to eating breakfast, which showed a significant reduction in BMI Z score ( $\beta$ : $-0.06,95 \% \mathrm{Cl}:-0.11,-0.01, p=0.02)$. (Supplemental Table 3)

\section{$\underline{\text { Table } 3}$}

\section{Association Between Target Behavior Attainment as an Exposure and BMI Z-score}




\begin{tabular}{|llll|}
\hline Exposure & $\boldsymbol{\beta}$ & $95 \% \mathrm{Cl}$ & $\boldsymbol{P}$-value \\
\hline Composite score* & -0.01 & $(-0.03,0.01)$ & 0.367 \\
\hline Breakfast & -0.04 & $(-0.09,0.02)$ & 0.196 \\
\hline Lunch & -0.02 & $(-0.07,0.03)$ & 0.416 \\
\hline Breakfast \& lunch & -0.01 & $(-0.07,0.04)$ & 0.635 \\
\hline Fruit & 0 & $(-0.04,0.04)$ & 0.99 \\
\hline Vegetable & -0.03 & $(-0.08,0.02)$ & 0.248 \\
\hline Sugar free beverage & -0.02 & $(-0.07,0.03)$ & 0.352 \\
\hline Sugary beverage & 0.02 & $(-0.03,0.07)$ & 0.519 \\
\hline Sugar free and sugary beverage & 0.04 & $(-0.03,0.11)$ & 0.284 \\
\hline Sleep & -0.05 & $(-0.1,-0.003)$ & 0.038 \\
\hline Physical activity & -0.03 & $(-0.08,0.03)$ & 0.374 \\
\hline Unhealthy snacks & 0.04 & $(-0.01,0.08)$ & 0.13 \\
\hline Fast Food & 0.02 & $(-0.02,0.07)$ & 0.32 \\
\hline Unhealthy snack and fast food & 0.04 & $(-0.01,0.09)$ & 0.132 \\
\hline
\end{tabular}

\section{Limitations And Lessons Learned}

Study limitations relate predominantly to two areas: 1) availability of onsite staff to implement program components discretely and its impact on the study design, and 2) challenges in use of existing data sources to evaluate program impact.

Programming and data collection for the enhanced $B^{\prime} N$ Fit POWER program was conducted routinely by school-based afterschool staff without expert-level training. The afterschool program administration prioritized hiring a part-time program monitor to work with the existing educational consultant to design biweekly training sessions to support preparation of youth leaders to implement the curriculum, but did not have resources to consistently directly observe youth leader curriculum implementation.

While abstraction of existing EMR clinical BMI data was routine, abstraction of target behavior data was more challenging. Levels of self-reported target behavior attainment were assessed using the B'N Fit POWER surveys embedded into different activities that utilize different data collection and storage strategies: afterschool activities used paper and electronic surveys while SBHC data was from electronic clinic visits.

Afterschool program activities attendance data did not distinguish which leadership attendance hours each week consisted of physical activity attendance and adjustments in daily activities reflecting individual student preferences were not recorded. For example, a student scheduled for basketball may decide to attend art that day with their friend after they were marked present for the basketball session. This flexibility may be a reason that overall physical activity attendance was only $38 \%$ of expected. Conversely, all afterschool program students were required to remain with their assigned leadership group for leadership sessions throughout the year making it easier to track attendance at leadership sessions. The imposition of a more consistent and less flexible schedule for the $B^{\prime} N$ Fit POWER students with a higher physical activity attendance requirement may contribute to significantly more hours of physical activity attendance moving forward.

An important lesson learned relates to basing the attainment of target behavior goals on "ideal" or recommended target behaviors. Given that our baseline behaviors in this cohort were far from ideal, with a compostite score of 2.5 out of 7 at baseline, attainment of the target behaviors may have been unrealistic to expect at this point. In this instance, any improvement that was less than "ideal", even if positive, would not be assessed as a positive change. For example, with attainment of the vegetable consumption goal set at three or more servings a day, an individual with an increase from zero servings at baseline to two servings following participation, would not be assessed as attaining the target behavior, although clearly there is an improvement noted. The addition of personalized feedback and target behavior planning via web-based surveys and personalized reports, may better capture smaller individual improvements that support the development of realistic target behavior goals as a first step to reaching the "ideal" target behavior goals.[39]

\section{Discussion}

Consistent with the upward trend of more severe forms of pediatric obesity,[3] and with current estimates that more than half of American children today will be obese by the age of 35,[7] it is not surprising that $56 \%$ of this cohort demonstrated an increase in BMI z-score over time. Yet, $44 \%$ of youth with overweight or obesity participating in B'N Fit POWER demonstrated either maintenance or improvement in BMI z-score. Further, consistent with increased unhealthy snacking and fast food consumption secular trends and declining sleep hours among American youth and high levels of sugary beverage consumption among black and Hispanic youth,[40-44] this cohort demonstrated cross-sectional declines in the proportion attaining target behaviors with age at baseline.

The upward secular trend of unhealthy behaviors may be related to adolescent rites of passage associated with increasing autonomy, independence, and peer influence among middle school students. Increasing water or sugar-free beverage consumption may be easier to attain than decreasing sugary beverage consumption given the high availability of sugary beverages relative to bottled water beverages and the relative ease of adopting a new healthy behavior 
compared to stopping an unhealthy behavior.[45] Further, the longstanding poverty stigma of school lunch, and students not wanting to be seen as poor, may explain a tendency for students to forego lunch and opt for fast food meals afterschool.[46] The consumption of sugary beverages and fast food likely occurs once students leave school and as students become older with increasing independence to purchase food and beverages outside the school or home.

Students with higher afterschool attendance $(\geq 75 \%)$ had higher composite score improvement, greater BMI Z score improvement, and greater target behavior improvements in a majority of behaviors compared to students with lower afterschool attendance. We also demonstrated that the ability to track weekly leadership and physical activity attendance rates and repeated target behavior measures over the academic year provides program administrators with the tools to track the impact of program changes that result in improvements in program attendance over time and its impact on target behaviors.

Together these findings support implementation of concrete guidelines for a minimum of 1.5 hours required weekly hours of healthy lifestyle education (during B'N Fit POWER leadership curriculum and cooking class,) and 4.25 hours of physical activity during middle school afterschool programming where the majority of students will engage in recommended activities.

\section{Conclusion}

A recent community needs assessment conducted by our institution indicated that top community-member priorities include concerns related to food and nutrition and obesity and community-recommended response actions include the need for activities that increase access to healthier food, exercise, and weight loss programs.[27]

Adding structured nutrition education and requiring a minimum required number of physical activity hours for existing middle school afterschool programming is a change easily implemented by school administrators. We show that this increases attainment of a number of healthy target behaviors, particularly those students with overweight and obesity. Improvement in target behaviors, in turn, is associated with improvements in outcomes (BMI z-score). We document that participation in any amount of structured healthy lifestyle programming may positively impact improvements in behaviors and BMI z-score. Despite these limitations, in an era where there continues to be a paucity of evidence for health promoting programs in schools, our findings of overall improvements support continued program implementation.[47] Interventions during emerging adolescence in the middle school environment can potentially mitigate the current trajectory of adoption of unhealthy lifestyle behaviors. These are simple initiatives at a point where an intervention might have a positive spillover effect to promote normalization of healthy lifestyle behaviors and ultimately flatten the obesity epidemic ravaging low income predominantly minority communities.

\section{Abbreviations}

Acronyms: SES ( Socioeconomic status), USPSTF ( United States Preventative Services Task Force), DM (Diabetes Mellitus), BMI (Body Mass Index), Community Preventive Services Task Force (CPSTF, B'N Fit (Bronx Nutrition and Fitness Initiative for Teens), HIPAA (Health Insurance Portability and Accountability Act of 1996), SBHC (School-Based Health Center), NY ( New York), NYC ( New York City) PS/MS (Public School/ Middle School), DOE ( Department of Education), USDA (United States Department of Agriculture), MMCC (Mosholu Montefiore Community Center), WITS (Wellness in the Schools), MSHP (Montefiore School Health Program), NYC DYCD ( New York City Department of Youth and Community Development), NHLBI (National Heart, Lung, and Blood Institute, STEM (Science, Technology, Engineering and Mathematics), EHR (Electronic Health Record), SFSB (Sugar-free beverage and sugary beverage consumption), USFF (Unhealthy snack food and fast food consumption)

\section{Declarations}

\section{Ethics approval and consent to participate}

The study was approved by the Albert Einstein College of Medicine Office of Human Research Affairs (OHRA) and the human subjects consent for procedures followed were in accordance with the ethical standards of the OHRA and with the Helsinki Declaration of 1975, as revised in 2013.All study participants underwent informed consent in compliance with the privacy and confidentiality requirements outlined in the Recommendations for the Conduct, Reporting, Editing and Publication of Scholarly Work in Medical Journals [International Committee of Medical Journal Editors (ICMJE) Recommendations)] otherwise known as the Uniform Requirements for Manuscripts (URMs). (http://www.icmje.org/icmje-recommendations.pdf)

\section{Consent for publication}

\section{Not applicable}

\section{Availability of data and materials}

\section{The datasets used and/or analysed during the current study are available from the corresponding author on reasonable request.}

\section{Competing interests}

The authors declare that they have no competing interests. All authors of declare that there is no conflict of interest regarding the publication of this article and this article has not been published elsewhere.

\section{Funding}


We express our appreciation for funding supported by a Human Resources and Services Administration (HRSA) Healthy Tomorrows Partnership for Children Program grant (Grant Number H17MC29435) and the Life Course Methodology Core (LCMC) of the New York Regional Center for Diabetes Translation Research via a grant from the National Institute of Diabetes and Digestive and Kidney Diseases (grant numbers DK111022- 8786 and P30 DK111022).

\section{Authors' contributions}

JR contributed to study design, implementation and oversight of data collection and interpretation, and writing and substantively revising the manuscript. JYM and VS contributed to data cleaning, analysis, and interpretation and writing of statistical methods and results section of the paper. JJ contributed to data collection, cleaning, analysis and writing initial draft of manuscript. PM and JWR contributed to study conception and design and substantive revision of the paper. EJK, SD, and BF contributed substantively to data acquisition. All authors read and approved the final manuscript.

\section{Acknowledgements}

We express our appreciation to our collaborators at Public School/Middle School-95, the Mosholu Montefiore Community Center, the Montefiore School Health Program, and Wellness in the Schools.

\section{References}

1. Ogden CL, Carroll MD, Lawman HG, Fryar CD, Kruszon-Moran D, Kit BK, et al. Trends in obesity prevalence among children and adolescents in the United States, 1988-1994 through 2013-2014. JAMA. 2016;315(21):2292-9.

2. Skinner AC, Ravanbakht SN, Skelton JA, Perrin EM, Armstrong SC. Erratum: Prevalence of obesity and severe obesity in US children, 1999-2016. Pediatrics. 2018;141(3):e20173459.

3. Skinner AC, Skelton JA. Prevalence and trends in obesity and severe obesity among children in the united states, 1999-2012. JAMA Pediatr. 2014;168(6):561-6.

4. Seo DC, King MH, Kim N, Sovinski D, Meade R, Lederer AM. Predictors for persistent overweight, deteriorated weight status, and improved weight status during 18 months in a school-based longitudinal cohort. Am J Heal Promot. 2015;30(1):22-7.

5. Watson KB, Harris CD, Carlson SA, Dorn JM, Fulton JE. Disparities in adolescents' residence in neighborhoods supportive of physical activity - United States, 2011-2012. MMWR Morb Mortal Wkly Rep. 2016;65(23):598-601.

6. Atkiss K, Moyer M, Desai M, Roland M. Positive youth development. Am J Heal Educ. 2011;42(3):171-80.

7. Ward ZJ, Long MW, Resch SC, Giles CM, Cradock AL, Gortmaker SL. Simulation of growth trajectories of childhood obesity into adulthood. N Engl J Med. 2017;377(22):2145-53.

8. Grossman DC, Bibbins-Domingo K, Curry SJ, Barry MJ, Davidson KW, Doubeni CA, et al. Screening for obesity in children and adolescents us preventive services task force recommendation statement. JAMA. 2017;317(23):2417-26.

9. Seo DC, Sa J. A meta-analysis of obesity interventions among US minority children. J Adolesc Health. 2010;46(4):309-23.

10. Wilson DK. New perspectives on health disparities and obesity interventions in youth. J Pediatr Psychol. 2009;34(3):231-44.

11. Barlow SE. Expert committee recommendations regarding the prevention, assessment, and treatment of child and adolescent overweight and obesity: summary report. Pediatrics 2007;120 Suppl 4:S164-92.

12. Whitlock EP, Williams SB, Gold R, Smith PR, Shipman SA. Screening and interventions for childhood overweight: A summary of evidence for the US Preventive Services Task Force. Pediatrics. 2005;116(1):e125-44.

13. Dao HH, Frelut ML, Oberlin F, Peres G, Bourgeois P, Navarro J. Effects of a multidisciplinary weight loss intervention on body composition in obese adolescents. Int J Obes. 2004;28(2):290-9.

14. Savoye M, Nowicka P, Shaw M, Yu S, Dziura J, Chavent G, et al. Long-term results of an obesity program in an ethnically diverse pediatric population. Pediatrics. 2011;127(3):402-10.

15. The Diabetes Control and Complications Trial Research Group. Lifetime benefits and costs of intensive therapy as practiced in the diabetes control and complications trial. JAMA. 1996;276(17):1409-15.

16. Belansky ES, Cutforth N, Delong E, Ross C, Scarbro S, Gilbert L, et al. Early impact of the federally mandated local wellness policy on physical activity in rural, low-income elementary schools in Colorado. J Public Health Policy 2009;30 Suppl 1:S141-60.

17. Foster GD, Sherman S, Borradaile KE, Grundy KM, Vander Veur SS, Nachmani J, et al. A policy-based school intervention to prevent overweight and obesity. Pediatrics. 2008;121(4):e794-802.

18. Gortmaker SL, Peterson K, Wiecha J, Sobol AM, Dixit S, Fox MK, et al. Reducing obesity via a school-based interdisciplinary intervention among youth: Planet Health. Arch Pediatr Adolesc Med. 1999;153(4):409-18.

19. Katz DL, O'Connell M, Yeh M-C, Nawaz H, Njike V, Anderson LM, et al. Public health strategies for preventing and controlling overweight and obesity in school and worksite settings: A report on recommendations of the Task Force on Community Preventive Services. MMWR Recomm Rep. 2005;54(RR10):1-12.

20. Kenney EL, Wintner S, Lee RM, Austin SB. Obesity prevention interventions in US public schools: Are schools using programs that promote weight stigma? Prev Chronic Dis. 2017;14:160605.

21. Rieder J, Cain A, Carson E, Benya A, Meissner P, Isasi CR, et al. Pilot project to integrate community and clinical level systems to address health disparities in the prevention and treatment of obesity among ethnic minority inner-city middle school students: lessons learned. J Obes. 2018; 
doi:10.1155/2018/6983936.

22. Rieder J, Meissner P, Shankar V, Moon J-Y, Wylie-Rosett J. A cascade model for school wellness programming: a feasibility case study. Heal Behav Policy Rev. 2020;7(1):38-50.

23. United States Census Bureau QuickFacts Bronx County. Bronx, New York. 2017. https://www.census.gov/quickfacts/bronxcountybronxboroughnewyork. Accessed 13 August 2020.

24. Smith S, Granja MR, Uyen SN. New York State profile of young children in deep poverty. New York: National Center for Children in Poverty, Mailman School of Public Health, Columbia University. 2017. http://www.nccp.org/publications/pdf/text_1190.pdf. Accessed 13 August 2020.

25. State Labor Department Releases Preliminary June 2020 Area Unemployment Rates. NY Department of Labor. 2020. https://www.labor.ny.gov/stats/pressreleases/prlaus.shtm. Accessed 13 August 2020.

26. New York State community health indicator reports. Bronx County: Health status and social determinants of health. 2019. https://webbi1.health.ny.gov/SASStoredProcess/guest?_program=\%2FEBI\%2FPHIG\%2Fapps\%2Fchir_dashboard\%2Fchir_dashboard\&p=ch\&cos=58. Accessed 14 August 2020.

27. Community health needs assessment and implementation strategy report 2019-2021. Montefiore Medical Center. 2019. https://www.montefiore.org/documents/communityservices/MNR-MMV-Community-Health-Needs-Report-2019-2021.pdf. Accessed 14 August 2020.

28. Egger JR, Bartley K, Benson L, Bellino D, Kerker BD. Childhood obesity is a serious concern in New York City: higher levels of fitness associated with better academic performance. NYC Vital Signs. NYC DOHMH. 2009.

https://www.researchgate.net/publication/284902080_Childhood_obesity_is_a_serious_concern_in_New_York_City_higher_levels_of_fitness_associated_w Accessed 13 August 2020.

29. Robert Wood Johnson Foundation health outcomes: overall rank. Bronx, NY. 2017. https://www.countyhealthrankings.org/app/newyork/2017/rankings/bronx/county/outcomes/overall/snapshot. Accessed 13 August 2020.

30. Citizens' Committee for Children of NY Database. Obesity among public elementary and middle school students. 2011. https://data.cccnewyork.org/data/table/94/obesity-among-public-elementary-and-middle-school-students\#94/143/9/a/a\%0D. Accessed 13 August 2020.

31. Public School 95 Sheila Mencher in Bronx, NY. NY Department of Education. 2020. https://www.schools.nyc.gov/schools/X095. Accessed 14 August 2020.

32. Physical education: NYC fitnessgram. NYC Department of Education. 2020. https://www.schools.nyc.gov/learning/subjects/physical-education. Accessed 14 August 2020.

33. Physical activity guidelines for Americans: $2^{\text {nd }}$ edition. US Department of Health and Human Services. 2018. https://health.gov/sites/default/files/201909/Physical_Activity_Guidelines_2nd_edition.pdf. Accessed 13 August 2020.

34. Sleep deprivation and deficiency: How much sleep is enough? NIH. National Heart, Lung, and Blood Institute. https://www.nhlbi.nih.gov/healthtopics/sleep-deprivation-and-deficiency. Accessed 13 August 2020.

35. Choose MyPlate. USDA Food and Nutrition Service. https://www.fns.usda.gov/program/choose-myplate. Accessed 14 August 2020.

36. Kelly AS, Barlow SE, Rao G, Inge TH, Hayman LL, Steinberger J, et al. Severe obesity in children and adolescents: identification, associated health risks, and treatment approaches: a scientific statement from the American Heart Association. Circulation. 2013;128(15):1689-712.

37. Raghunathan T, Solenberger P, Berglund P, Van Hoewyk J. IVEware: Imputation and variance estimation software (version 0.3): complete user guide. Ann Arbor: Survey Research Center, University of Michigan. 2016. https://www.src.isr.umich.edu/wp-content/uploads/iveware-manual-Version-0.3.pdf. Accessed 13 August 2020.

38. R Core Team. R: A language and environment for statistical computing. R Foundation for Statistical Computing, Vienna, Austria. 2019. https://www.rproject.org. Accessed 14 August 2020.

39. Martin S, Heo M, Jimenez CC, Lim J, Lounsbury DW, Fredericks L, et al. Personalizing the dietary guidelines: use of a feedback report to help adolescent students plan health behaviors using a SMART goal approach. Child Adolesc Obes. 2019;2(1):47-62.

40. Matricciani L, Olds T, Petkov J. In search of lost sleep: secular trends in the sleep time of school-aged children and adolescents. Sleep Med. Rev. 2012;16(3):203-11.

41. Bleich SN, Vercammen KA, Koma JW, Li Z. Trends in beverage consumption among children and adults, 2003-2014. Obesity. 2018;26(2):432-41.

42. Jahns L, Siega-Riz AM, Popkin BM. The increasing prevalence of snacking among US children from 1977 to 1996. J Pediatr. 2001;138(4):493-8.

43. Piernas C, Popkin BM. Trends in snacking among US children. Health Aff. 2010;29(3):398-404.

44. Rehm CD, Drewnowski A. A new method to monitor the contribution of fast food restaurants to the diets of US children. PloS One. 2014;9(7):e103543.

45. Maillot M, Vieux F, Rehm CD, Rose CM, Drewnowski A. Consumption patterns of milk and $100 \%$ juice in relation to diet quality and body weight among United States children: analyses of NHANES 2011-16 data. Front Nutr. 2019;6:117.

46. One year later: A look at New York City public schools' free lunch program. Hunter College NYC Food Policy Center. 2018. https://www.nycfoodpolicy.org/new-york-city-public-schools-offer-free-lunch-to-all-students/. Accessed 13 August 2020.

47. McHugh C, Hurst A, Bethel A, Lloyd J, Logan S, Wyatt K. The impact of the World Health Organization Health Promoting Schools framework approach on diet and physical activity behaviours of adolescents in secondary schools: a systematic review. Public Health. 2020;182:116-24.

\section{Figures}



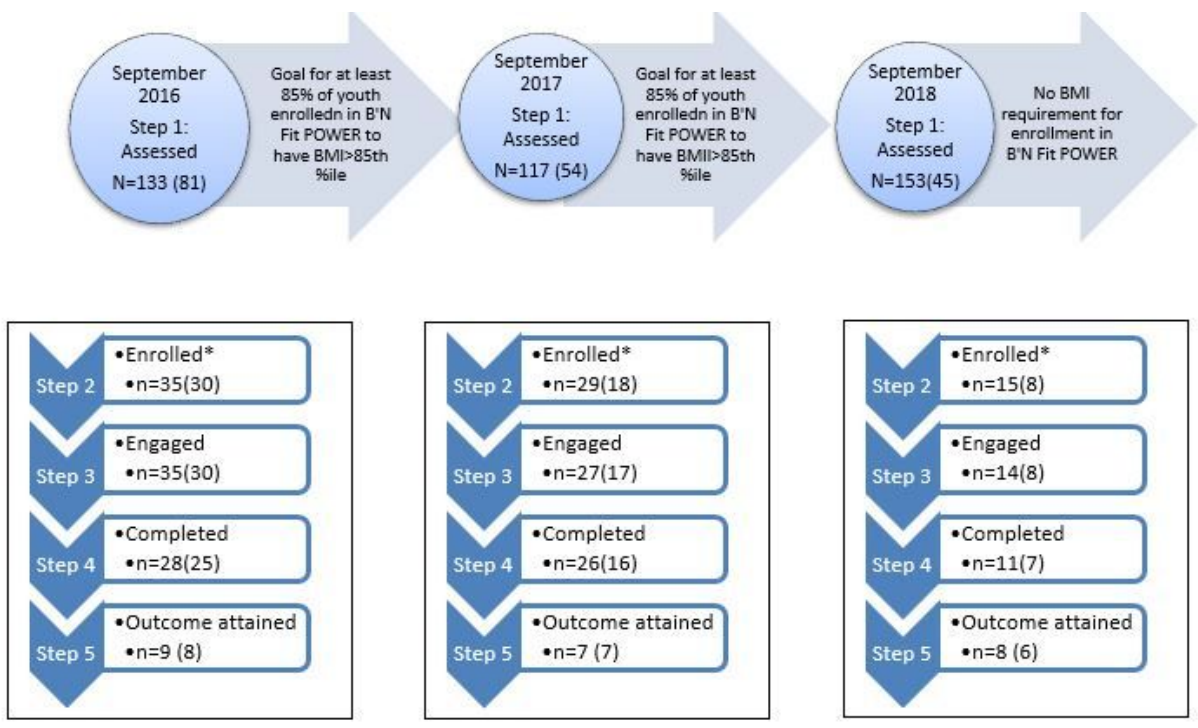

*B 'N Fit POWER enrollment restricted to 40 students each for 2016 and 2017 and 20 for 2018 based on staffing limitations. The numbers within the parenthesis reflect cascade target students whose BMI $\geq 85^{\text {th }}$ percentile.

\section{Figure 1}

Proportions of Students Attaining Step Milestones Each School Year

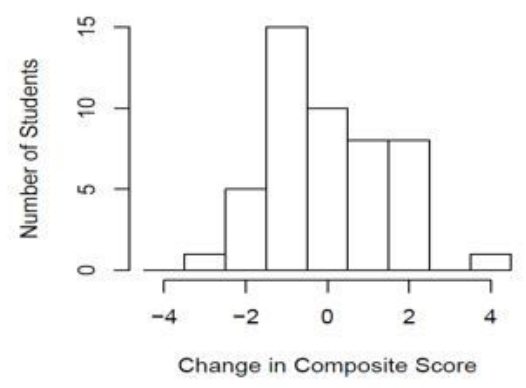

\section{Figure 2}

Composite Target Behavior Score Changes After a Year $(\mathrm{N}=76)$ 




Sugar-Free Bev. -Sugar-free beverage consumption; Sugary Bev. -Sugary beverage consumption; SFSB -Sugar-free beverage and sugary beverage consumption; USFF - Unhealthy snack food and fast food consumption.

${ }^{*} p=0.05$ Note: Target behaviors attainment standards according to American Academy of Pediatrics Expert Committee,

NHLBI sleep recommendations, Physical Activity Guidelines for Americans 2nd Edition; and USDA MyPlate guidelines.

\section{Figure 3}

Proportions of Students Attaining Individual Target Behaviors After One Year ( $\mathrm{N}=76)$

\section{Supplementary Files}

This is a list of supplementary files associated with this preprint. Click to download.

- AdditionalFile1.docx 